\title{
A Rare Association of Giant Cell Arteritis with Recurrent Corneal Ulcer
}

\author{
Sailaja Bondalapati1 ${ }^{*}$, Kay Khine ${ }^{2}$, Maya Bitar², David Chesnutt², Richard M. Davis ${ }^{2}$ \\ ${ }^{1}$ University of North Carolina School of Medicine, Chapel Hill, NC, USA \\ ${ }^{2}$ Department of Ophthalmology, University of North Carolina Hospitals, Chapel Hill, NC, USA \\ Email: "bondalapati29@gmail.com
}

Received 8 June 2016; accepted 31 July 2016; published 3 August 2016

Copyright (C) 2016 by authors and Scientific Research Publishing Inc.

This work is licensed under the Creative Commons Attribution International License (CC BY).

http://creativecommons.org/licenses/by/4.0/

(c) (i) Open Access

\begin{abstract}
We report a rare case of association of temporal arteritis with recurrent central corneal ulcer. A 91-year-old male with a remote history of clinically diagnosed giant cell arteritis (GCA) and penetrating keratoplasty (PK) for corneal edema in 1990's in the left eye presented with irritation and severe dry eye. He progressively developed central corneal ulcer regardless of treatment with aggressive lubrication and patching. The clinical course, blood tests and temporal artery biopsy results yielded the diagnosis of recurrent GCA. The clinical course improved after starting oral steroids. The case report illustrates the importance of ruling out GCA in patients with recurrent corneal ulcers and history of GCA. It also highlights the significance of shared understanding between primary care physicians and specialists to handle common and chronic diseases to make efficient diagnoses and plan treatment regimens. This is the first plausible case of reported GCA association with central corneal ulcer in the United States.
\end{abstract}

\section{Keywords}

Giant Cell Arteritis, Temporal Arteritis, Central Corneal Ulcer, Sterile Ulcer

\section{Introduction}

Giant cell arteritis is a vasculitis of medium and large size arteries, predominantly involving the carotid artery system extending to the temporal artery and branches of the ophthalmic artery. In individuals aged 50 years or older, the average incidence was 18.3 per 100,000 inhabitants with 25 for women and 9.3 for men [1]. The classic symptoms include headache, scalp tenderness, tongue and jaw claudication, and loss of vision. Nonspecific constitutional symptoms such as fever and weight loss are also often reported. Polymyalgia rheumatic (PR)

\footnotetext{
*Corresponding author.
}

How to cite this paper: Bondalapati, S., Khine, K., Bitar, M., Chesnutt, D. and Davis, R.M. (2016) A Rare Association of Giant Cell Arteritis with Recurrent Corneal Ulcer. Open Journal of Ophthalmology, 6, 144-149. 
symptoms such as tenderness and pain in the shoulder need attention as these are observed in $50 \%$ of the cases with biopsy proven GCA [2] [3].

Most common signs are vision loss, thickened, dilated and occasionally erythematous temporal artery with reduced or absent pulse, and tender palpable nodules [2]. The frequency of the other ocular manifestations in GCA isreported as $12.2 \%$ central retinal artery occlusion (CRAO), $21.2 \%$ cilioretinal artery occlusion, $76.4 \%$ anterior ischemic optic neuropathy (AION), 5.7\% posterior ischemic optic neuropathy, 31\% amaurosisfugax, 6\% diplopia, and rarely anterior segment ischemia [4]. Previously in literature, the presentation of GCA with unusual anterior segment signs, such as limbal guttering [5], scleritis [6], corneal edema [7] and peripheral ulcerative keratitis (PUK) [8], have been reported but not recurrent central corneal ulcer. We document here such a case in a patient with GCA.

\section{Case Report}

A 91-year-old Caucasian male with ocular history of primary open angle glaucomain the right eye (OD), mixed mechanism glaucoma in the left eye (OS) and dry eye in both eyes(OU), presented with severe irritation OS. He had a past ocular surgical history of cataract extraction OU and corneal transplantation OS more than twenty years ago for corneal edema. Of note, he had a history of non-biopsy proven GCA, which was diagnosed a decade ago based on symptoms. He was treated at that time with a short course of prednisone. Other medical and surgical history included hypertension controlled on medication, osteoarthritis, prostate cancer under treatment with androgen deprivation therapy, and knee replacement surgery. His current ocular medications consisted of dorzolamide/timolol for glaucoma and artificial tears for dry eyes.

At this visit, best corrected visual acuity (BCVA) was 20/50 and 20/200 with intraocular pressures (IOP) of $20 \mathrm{mmHg}$ and $11 \mathrm{mmHg}$ in the OD and OS respectively. Slit lamp exam (SLE) showed no lagophthalmos and normal conjunctiva with good tear lakes OU. The cornea OD had some superficial punctate epitheliopathy (SPE). The graft OS had a $6 \mathrm{~mm} \times 5 \mathrm{~mm}$ paracentral epithelial defect involving stroma with adjacent peripheral neovascularization butno infiltrate. The rest of the exam was unremarkable with deep and quiet anterior chamber, round iris and posterior chamber intraocular lens in good position OU. Fundus exam revealed cup to disc of 0.85 OD and 0.8 with superior thinning in the OS otherwise unremarkable posterior segment exam OU. The patient was treated with aggressive lubrication followed by eyelid patching for a few days. Epithelial defect improved but irritation worsened.

At the four-week follow-up, the patient reported pain in the left eye and left temple. Vision had deteriorated to hand motion OS. Examination revealed a hazy corneal graft OS with a descemetocele. Cyanoacrylate glue was used to stabilize the cornea and a contact lens was placed to prevent corneal perforation. Given the history of GCA, ESR was ordered and was found to be $65 \mathrm{~mm} / \mathrm{h}$. The patient was diagnosed with recurrence of GCA and treated with $40 \mathrm{mg}$ oral prednisone by his primary care physician (PCP). At one-month follow-up, prednisone was tapered to $10 \mathrm{mg}$ maintenance dose as patient had clinically improved with visual acuity 20/400. On exam, the central cornea was $90 \%$ epithelialized with a small residual epithelial defect inferonasally with, persistent haze and neovascularization shown in Figure 1.

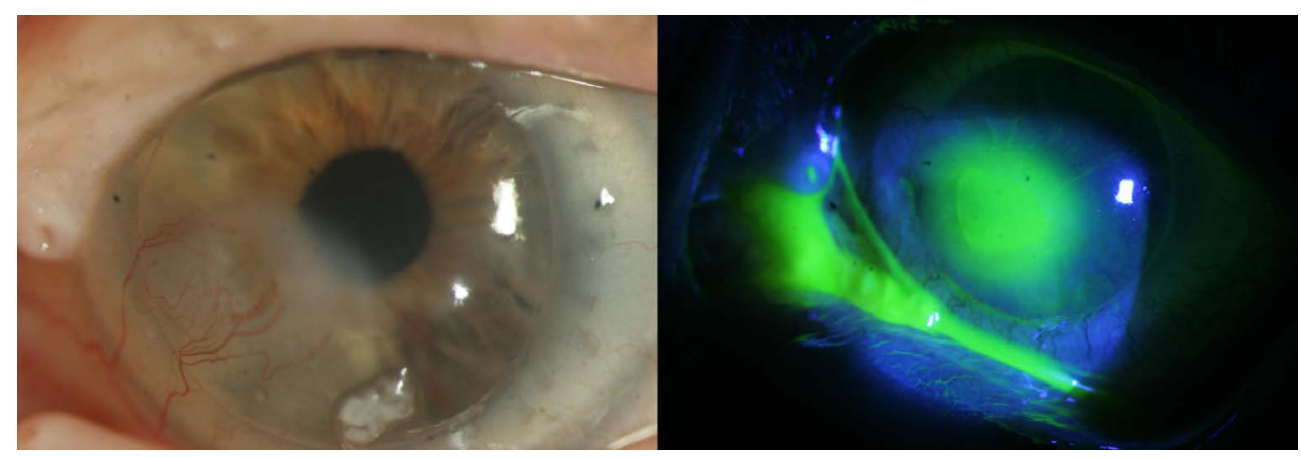

(a)

(b)

Figure 1. Slit lamp images of left eye at the time of the first ulcer episode showing (a) Corneal neovascularization from 7'o clock to 9'o clock position and inferonasal ulcer encroaching visual axis. (b) Persistent epithelial defect enhanced with fluorescein stain. 
A year later, patient was doing well with no epithelial defect and was still treated with $10 \mathrm{mg}$ maintenance dose steroids. However, there was persistent haze and neovascularization OS necessitating repeat penetrating keratoplasty (PK). The surgical pathology specimen had moderate loss of endothelium and focal scarring. At one-month follow-up, the graft was still very edematous with neovascularization. As a result of this graft failure, the patient underwent repeat PK. His BCVA improved to 20/40 OS. Six months after repeat PK, his new PCP was concerned about worsening osteoporosis from chronic steroid use and decided to discontinue prednisone treatment. The PCP ordered ESR and CRP. The results were within normal lab reference range $(8 \mathrm{~mm} / \mathrm{hr}$ and 0.6 $\mathrm{mg} / \mathrm{L}$ respectively) and prednisone was tapered. Two weeks after stopping steroids, patient presented with worsening left eye irritation. On examination, BCVA was 20/200 OS with diffuse SPE in the graft. He was treated for dry eyes with aggressive gel lubrication. Four-week slater, patient came in complaining persistent left eye irritation with left scalp tenderness and fatigue. Visual acuity was stable at 20/200 OS. Examination revealed a central corneal epithelial defect with stromal thinning but no infiltrate, no neovascularization and noanterior chamber inflammation. A soft contact lens was placed for two days, which did not resolve the central ulcer. Hence, contact lens was removed and the eye was patched for 48 hours. Patient was restarted on oral prednisone at a dose of $20 \mathrm{mg}$ and it was increased to $40 \mathrm{mg}$ a few days later because of lack of improvement. At one-week follow-up, the left cornea had developed a descemetocele necessitating placement of cyanoacrylate glue and a contact lens as seen in Figure 2.

Laboratory testing was performed. ESR and CRP were within the normal reference. Anti-nuclear antibody (ANA)was positive with speckled pattern and a titer of 1:160. Speckled pattern is associated with many conditions including lupus, Sjogren's, mixed connective tissue disease, scleroderma, and polymyositis/dermatomyositis but not specific to any autoimmune disease. In our patient, Extractable nuclear antigen (ENA), which is a marker for above immune disorders, was negative. Since the suspicion for recurrent GCA was high, temporal artery biopsy (TAB) was performed. The result revealed focal peri-internal elastica fibrosis including foci of medial fibrosis supporting diagnosis of healed arteritisas perceived in Figure 3. In the next four weeks, symptoms improved, visual acuity was count fingers at one foot and the ulcer consolidated. Findings were communicated to the PCP who then agreed to continue the steroid treatment. Prednisone was tapered to a $20 \mathrm{mg}$ maintenance dose. At eight-week follow-up, the contact lens and glue were in place, graft was clear peripherally with neovascularization at 9, 10 and $11^{\prime} 0$ clock positions and visual acuity was stable but the eye was still tender to touch. Prednisone was increased to $30 \mathrm{mg}$ with plan for slow taper in the future. At eleven-week follow-up with neuro-ophthalmology, patient reported taking $15 \mathrm{mg}$ prednisone daily and that his headaches had stopped. Visual acuity was unchanged with normal IOP in the OS.

\section{Discussion}

The clinical criteria established by the American College of Rheumatology (ACR) for diagnosis of GCA is: 1) age $\geq 50$ years, 2) new onset localized headaches, 3) temporal artery tenderness or decreased temporal artery pulse, 4) ESR $\geq 50 \mathrm{~mm} / \mathrm{h}$ and 5) superficial TAB consistent with GCA [9]. The presence of three of the five criteria was calculated to yield a 93.5\% sensitivity and 91.2\% specificity [9]. However, Murchisen et al. found that

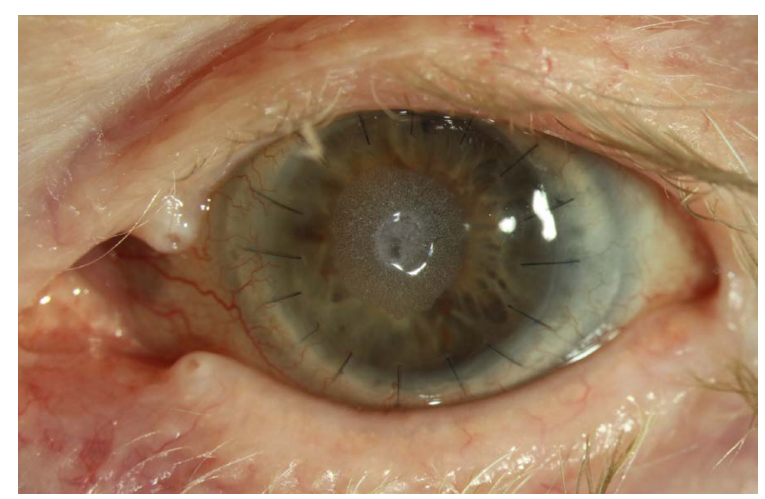

Figure 2. Left eye after the repeat corneal transplant; at two-week follow-up after sealing the ulcer with cyanoacrylate glue and contact lens placement. 


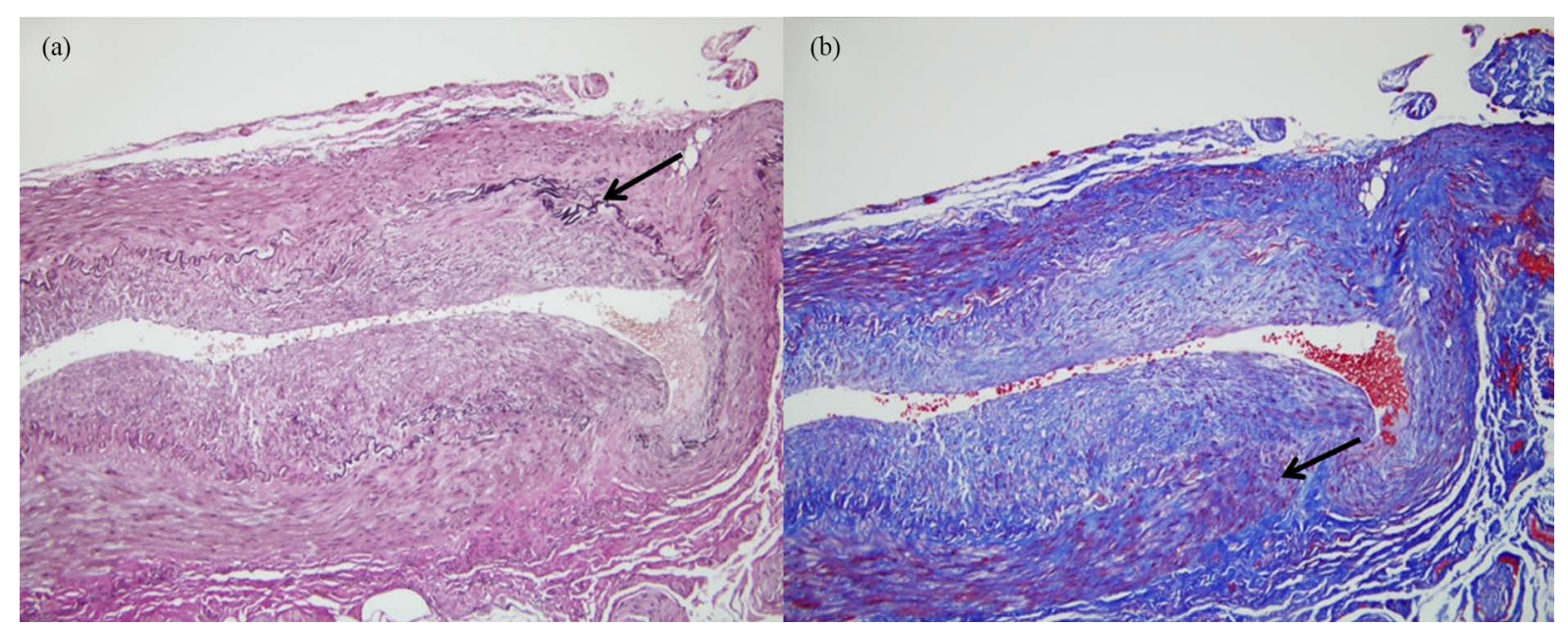

Figure 3. (a) The von geison stain (black) highlights focal disruptions in the internal elastic lamina; (b) The trichrome stain (blue) shows mild focal fibrosis (arrow) in the tunica media.

the use of ACR criteria alone could miss up to 25\% of GCA diagnosis [10] [11]. Hayreh et al. also reviewed ACR guidelines and reflected that it did not include other important clinical criteria such as jaw claudication, neck pain and therefore suggested revision [4]. Blood tests for ESR and CRP are highly useful in the diagnosis of GCA, although neither of them is $100 \%$ sensitive and specific but together provides the best specificity of $97 \%$ [4]. Hence, Hayreh et al. recommended using both ESR and CRP for diagnosis and management of GCA [4]. Biopsy of the temporal artery is the gold standard for diagnosis of GCA. Initiation of high dose steroid treatment before confirming the diagnosis is warranted to protect the residual vision in the affected eye and the fellow eye. GCA patients usually need steroid treatment for much longer than two years with median lowest dose of 7 mg/day (range 1 - 16 mg/day) [4]. To maintain the lowest levels of ESR and CRP and to keep GCA under control, most patients require a small maintenance dose indefinitely for variable duration [4].

In our patient, the signs and symptoms were atypical and recurrence of GCA was unusual after a decade. He presented with recurrent central corneal melting, mild tenderness of temporal arteries and hip pain but denied other GCA associated symptoms. His ESR and CRP were normal but they were tested a couple days after restarting the steroid which may have affected the result. Negative ENA rendered other autoimmune diseases known to be associated with recurrent corneal melting like SLE and Sjogren's less likely. The absence of symmetric and small joint pains ruled out rheumatoid arthritis. Positive TAB confirmed the diagnosis of recurrent GCA. Alba et al. reported 36\% relapse of GCA in two or more years in a cohort study that followed patients for $7.8 \pm 3.3$ years [12]. The longest time for relapse reported in the literature was 21 years after initial diagnosis and presented with an unusual sign of leg ulcer [13]. Vague symptoms and atypical signs of GCA at relapse can mislead physicians, especially if the history of GCA is remote and no clear records are available. This may delay the diagnosis and proper treatment. Increased awareness is required for prompt recognition of this potentially devastating disease because transient monocular vision loss may be a warning symptom before permanent vision loss occurs.

In our patient, the mechanism of corneal ulcer is unclear. It could be due to hypoxia secondary to ischemia of the limbal circulation from vasculitis. Subclinical autoimmune disease with positive ANA could also be causing deposition of immune complexes in the cornea. Affected epithelium, keratocytes, and recruited inflammatory cells might be releasing matrix metalloproteinases (MMP), which would degrade collagen and the extracellular matrix. It is also possible that autoantibodies target corneal epithelium as hypothesized in peripheral ulcerative keratitis [14] although the ulcer was more central in our case. Avascular cornea can limit the efficiency of effector cell recruitment although neutrophils, monocytes and lymphocytes can readily migrate through stroma when appropriate chemotactic stimuli are activated [15].

This case report reiterates that integrated clinical care plays a vital role in the successful management of patients' health as stopping the prednisone precipitated the recurrence of the corneal ulcer. Effective communication between primary care physicians and specialists regarding patient referrals and consultations is necessary for coordinated care and it improves patient outcomes and physician satisfaction [16]. 
To our knowledge, this is the first case report which illustrates a rare association of central corneal ulcer with GCA. Early recognition of such rare associations is important for prompt treatment and good visual outcome of the patients.

\section{Acknowledgements}

The authors would like to thank Dr. O’Rese Knight for his involvement in the case with glaucoma work up.

\section{Conflicts of Interest}

This report has no potential financial conflicts of interest.

\section{References}

[1] Nordborg, E. and Bengtsson, B.A. (1990) Epidemiology of Biopsy-Proven Giant Cell Arteritis (GCA). Journal of Internal Medicine, 227, 233-236. http://dx.doi.org/10.1111/j.1365-2796.1990.tb00150.x

[2] Salvarani, C., Cantini, F., Boiardi, L. and Hunder, G.G. (2002) Polymyalgia Rheumatica and Giant-Cell Arteritis. New England Journal of Medicine, 347, 261-271. http://dx.doi.org/10.1056/NEJMra011913

[3] Gonzalez-Gay, M.A. (2004) Giant Cell Arteritis and Polymyalgia Rheumatica: Two Different but Often Overlapping Conditions. Seminars in Arthritis and Rheumatism, 33, 289-293. http://dx.doi.org/10.1016/j.semarthrit.2003.09.007

[4] Hayreh, S.S. and Zimmerman, B. (2003) Management of Giant Cell Arteritis. Our 27-Year Clinical Study: New Light on Old Controversies. Ophthalmologica, 217, 239-259. http://dx.doi.org/10.1159/000070631

[5] Gerstle, C.C. and Friedman, A.H. (1980) Marginal Corneal Ulceration (Limbal Guttering) as a Presenting Sign of Temporal Arteritis. Ophthalmology, 87, 1173-1176. http://dx.doi.org/10.1016/S0161-6420(80)35109-9

[6] Long, R.G., Friedmann, A.I. and James, D.G. (1976) Scleritis and Temporal Arteritis. Postgraduate Medical Journal, 52, 689-692. http://dx.doi.org/10.1136/pgmj.52.613.689

[7] Casson, R.J., Fleming, F.K., Shaikh, A. and James, B. (2001) Bilateral Ocular Ischemic Syndrome Secondary to Giant Cell Arteritis. Archives of Ophthalmology, 119, 306-307.

[8] Papathanassiou, M., Elezoglu, A., Nikita, E., Theodossiadis, P.G. and Vergados, I. (2009) A Rare Case of Peripheral Ulcerative Keratitis in Temporal Arteritis. European Journal of Ophthalmology, 19, 866-869.

[9] Hunder, G.G., Bloch, D.A., Michel, B.A., Stevens, M.B., Arend, W.P., Calabrese, L.H., et al. (1990) The American College of Rheumatology 1990 Criteria for the Classification of Giant Cell Arteritis. Arthritis \& Rheumatology, 33, 1122-1128. http://dx.doi.org/10.1002/art.1780330810

[10] Murchison, A.P., Gilbert, M.E., Bilyk, J.R., Eagle Jr., R.C., Pueyo, V., Sergott, R.C., et al. (2012) Validity of the American College of Rheumatology Criteria for the Diagnosis of Giant Cell Arteritis. American Journal of Ophthalmology, 154, 722-729. http://dx.doi.org/10.1016/j.ajo.2012.03.045

[11] Hayreh, S.S., Podhajsky, P.A. and Zimmerman, B. (1998) Occult Giant Cell Arteritis: Ocular Manifestations. American Journal of Ophthalmology, 125, 521-526. http://dx.doi.org/10.1016/S0002-9394(99)80193-7

[12] Alba, M.A., Garcia-Martinez, A., Prieto-Gonzalez, S., Tavera-Bahillo, I., Corbera-Bellalta, M., Planas-Rigol, E., et al. (2014) Relapses in Patients with Giant Cell Arteritis: Prevalence, Characteristics, and Associated Clinical Findings in a Longitudinally Followed Cohort of 106 Patients. Medicine (Baltimore), 93, 194-201. http://dx.doi.org/10.1097/MD.0000000000000033

[13] Misciali, C., Tengattini, V., Baraldi, C., Magnani, L. and Patrizi, A. (2013) Leg Ulcers Associated with Giant Cell Arteritis Relapse. The International Journal of Lower Extremity Wounds, 12, 69-70. http://dx.doi.org/10.1177/1534734613476518

[14] Messmer, E.M. and Foster, C.S. (1999) Vasculitic Peripheral Ulcerative Keratitis. Survey of Ophthalmology, 43, 379396. http://dx.doi.org/10.1016/S0039-6257(98)00051-4

[15] Liesegang, T., Skuta, G. and Cantor, L. (2007-2008) Intraocular Inflammation and Uveitis. Americal Academy of Ophthlamology, Sanfrancisco.

[16] Forrest, C.B., Glade, G.B., Baker, A.E., Bocian, A., von Schrader, S. and Starfield, B. (2000) Coordination of Specialty Referrals and Physician Satisfaction with Referral Care. Archives of Pediatrics and Adolescent Medicine, 154, 499-506. http://dx.doi.org/10.1001/archpedi.154.5.499 


\author{
Abbreviation List \\ GCA-Giant Cell Arteritis \\ PK-Penetrating Keratoplasty \\ PR-Polymyalgia Rheumatica \\ CRAO_-Central Retinal Artery Occlusion \\ AION-Anterior Ischemic Optic Neuropathy \\ PUK-Peripheral Ulcerative Keratitis \\ OD_Right Eye \\ OS-Left Eye \\ BCVA-Best Corrected Visual Acuity \\ IOP_-Intraocular Pressure \\ SLE-Slit Lamp Exam \\ SPE-Superficial Punctate Epitheliopathy \\ ESR-Erythrocyte Sedimentation Rate \\ CRP_C-Reactive Protein \\ PCP_-Primary Care Physician \\ ANA-Anti-Nuclear Antibody \\ ENA-Extractable Nuclear Antigen \\ ACR-American College of Rheumatology \\ TAB-Temporal Artery Biopsy \\ MMP_Matrix Metalloproteinases
}

\title{
Submit or recommend next manuscript to SCIRP and we will provide best service for you:
}

Accepting pre-submission inquiries through Email, Facebook, LinkedIn, Twitter, etc.

A wide selection of journals (inclusive of 9 subjects, more than 200 journals)

Providing 24-hour high-quality service

User-friendly online submission system

Fair and swift peer-review system

Efficient typesetting and proofreading procedure

Display of the result of downloads and visits, as well as the number of cited articles

Maximum dissemination of your research work

Submit your manuscript at: http://papersubmission.scirp.org/ 